\title{
The Effect of NelumboNucifera seeds and Hyphaene Thebaica on Induced Animal's Hyperlipidemia and Hypertension
}

\author{
Marwa F. Elmahdy ${ }^{1}$, Adris M.A ${ }^{2}$ \\ ${ }^{1}$ Faculty of Postgraduate, PhD student of Practical Biochemistry,Department of Biochemistry, Faculty of \\ Medicine, University of Al-Butana, ${ }^{2}$ Department Biochemistry, Faculty of Medicine, University of Al-Butana
}

\begin{abstract}
The life style of the people by large has been adversely affected due to manifold reasons which includes industrialization and eventually making obesity as a very fast growing epidemic worldwide. Consequence of overweight, results in chronic diseases like cardiovascular issues, diabetes, and cancer. Nearly every obese person is found to be hyperlipidemia, which indicates a condition of having high levels of cholesterol, cholesterol esters, triglycerides, low-density lipoprotein and depleted levels of high-density lipoprotein. The high frequency of side effects implications of the drugs available in the market has raised a dire need of discovering and developing a new novel drug. The studies show that the plants have proven to be an upright source of natural as well as multifunctional molecules. The natural molecules flavonoids along with other components have been reported for multi-functionality. HyphaeneThebaica and NelumboNucifera have direct lowering effect on blood lipids and hypertension. This review explains the effect of HyphaeneThebaica (Doum) and NelumboNucifera (Lotus seeds) on blood lipids and hypertension. Lipid profile will be evaluated by estimation of Cholesterol count, Triglycerides, High and low density lipoprotein while hypertension will be evaluated by measuring Aginotensin converting enzyme ( ACE) in serum and tissue extraction. Herbal medicine is the new good treatment for many chronic diseases to get ride from side effects of anticholestremic and anti-hypertension drugs.
\end{abstract}

Key words: Hyperlipidemia, Hypertension, Aginotensin converting enzyme (ACE), HyphaeneThebaica, Nelumbo Nucifera

\section{Introduction}

Plants have proven to be useful source of natural multifunctional molecules. Flavonoids along with a number of natural molecules have been reported to exhibit multi-functionality trait. The structural pattern of flavonoids influences the enzymatic activity of glucosidases and lipases. This can be useful for production and evolution of new drugs for many diseases caused by hyperlipidemia. The incorporation of medicine into food can add a new aspect to the existing drug market. The fate of accepting natural molecules as a remedy can be decided over acquiring the support of conducting large clinical studies checking the critical factors of toxicity as well as bioavailability. The researches have provided insights into the anti-potential of multifunctional natural molecules and elaborated some of the natural molecules in terms of bio-distribution and safety ${ }^{1}$. Herbal medicine still tops the list when it comes to the primary health care of about $65-80 \%$ of the globe's population. This is mainly observed in developing countries, due to improved cultural acceptability and showing more compatibility with human body and lesser side effects ${ }^{2}$. The drugs currently available have shown to bring about a number of side effects. Hyperlipidemia is illustrated by high serum lipids profile in circulated blood. It has been established that the greatest risk factors causing to commonness and severity of stroke, coronary heart diseases, hyperlipidemia and atherosclerosis are the primary cause of fatality. WHO reported that the high blood cholesterol contributes to approximately $56 \%$ of patients of cardiovascular diseases and about 4.4 million deaths every year ${ }^{3}$. 
High blood pressure is rightly termed as a "silent killer" as it comes up with no warning signs or symptoms whatsoever. Hypertension stands as the most common reason of premature death worldwide. An estimated amount of around one billion people are suffering from hypertension and two-thirds of them are found in developing countries. There is association between hyperlipidemia and hypertension as it is prevalent in hypertension ${ }^{4}$. Diabetes mellitus is one of common chronic metabolic disease spread all over the world cause intolerance deal with glucose due to absence of or deficiency of insulin 5 .

\section{HyphaeneThebaica and NelumboNucifera:}

Both are herbal medicine Plants which are the choice of drugs which represented the most potential field of alternative medicine. Many peoples depend on traditional system of medicine to maintain their physical and psychological health. Both are herbal medicine plants which are the choice of drugs that represent the most potential field of alternative medicine. Many peoples depend on traditional system of medicine to maintain their physical and psychological health ${ }^{5}$.

NelumboNucifera is a part of the family of Nelumbonaceae, which has various local names (Bean of India, Indian Lotus, scared lotus and Chinese water lily) ${ }^{6}$. HyphaeneThebaica is an African palm tree. It grows in riparian areas and along the coast of east, central and West Africa. It is sweet and called "Doum Fruit"7.

Chemical composition and pharmacological effects of the both medical plants:

The phytochemical constituents of these medical plants reflect their medical importance. NelumboNucifera phytochemical composition were flavonoids, alkaloids, steroids, glycosides, terpenoids and tannins. The proximate constituents were calcium, iron, crude protein, ash, crude fibers, crude fats and vitamin $\mathrm{C}^{8}$.

The epidemiological studies have shown that phytochemical components possess rich antioxidant properties and have been reported to exert multiple biological effects including antimicrobial, antiinflammatory activities, free radical scavenger, pain reliever, tranquilizer and metal chelators. They are effective in reducing cardio-cerebrovascular diseases, cancer mortality, hypercholesterolemia and antibiotic properties ${ }^{9}$. The process of thin-layer chromatography identified that the doum fruit contains significant amounts of flavonoids, coumarins, hydroxyl cinnamates, saponins, and essential oils ${ }^{10}$.

H. Thebaica aids effectively in the treatment of bilharzias and hypertension. It also acts as a hematinic agent. The water extract of doum fruits possess the capability of lowering hyperlipidemia in nephrotic syndrome and also eliminates the risk of glomerulosclerosis and atherosclerosis. An option which is natural, safe and nontoxic, $H$. Thebaica fruit can emerge out as a potent alternative to be used for hypolipidemic drugs. Moreover, it is also quite capable to be used as a hypocholesterolemic agent, hematinic and hypolipidemic suspensions ${ }^{11}$.

Treatment properties of HyphaeneThebaicaand NelumboNucifera

Hyperlipidemia was defined as the low density lipoprotein (LDL), complete cholesterol, levels of the triglyceride, or the level of the lipoprotein more than the 90th percentile as per the comparative value to the expected sample population or as per the level of HDL which is supposed to be less over the 10th percentile once it is compared with the common and most general population $^{12}$.

Hyperlipidemia, that plays a vital and more important part as in the promotion of the atherosclerosis inside the vessels of blood in the body, can be a major reason for affecting the heart as well, and this can lead towards the abrupt increase in ischemia injury and this can also weird the response to cardiac protective interventions which can be assumed to be a ischemic pre-as well as post-conditioning of the heart. In association with the unavailability of obvious coronary artery stenosis, it can also be responsible for the long-term hyperlipidemia, 
which may be a reason for the accumulation of cardiac lipids and this can be made responsible for the affect cardiac function ${ }^{12}$. Most of $50 \%$ of hypertensive patients have underlying cardiovascular (CVS) risk factors which are; diabetes, Lipids disorders (LDL and TGs),obesity, metabolicsyndrome, unhealthy life, alcoholic intake. These risk factors cause increase in cerebrovascular and renal complications. Familial history of hypertension, hypercholesterolemia and diabetes play an important role in developing hypertension ${ }^{13}$.

Angiotensin-converting enzyme (ACE) provides the most important and main component of reninangiotensin system (RAS), that is responsible for the management of the blood pressure with the help of which the volume of all the fluids will be maintained inside the body. The main conversion of the hormone angiotensin is done towards the active vasoconstrictor angiotensin II. Because of this reason we can say that ACE will be able to increases blood pressure with the constriction of the vessels of blood. ACE inhibitors are well known for their behavior in contrast towards the pharmaceutical drugs which is used for the treatment of cardiovascular diseases. The location for all of them are in the main capillary inside the lungs and thus they are available in the endothelial and kidney epithelial cells ${ }^{14}$. Aginotensin converting Enzyme (ACE) is regulated by the effect of Hyphaene as it leads to regulation of hypertension ${ }^{7}$.

Since long times, it is supposed to be believed that the plants which have medicinal properties are an important source for the substances needed for the therapeutic effects. As per a general statistics we can predict that approximately $80 \%$ and more of the developing countries and their populations largely depends on the use of the elements available in the folk medicines for the problem resolution for heart related issues and cardio problems. There are many researches have been done to prove its efficacy and safety ${ }^{13}$.

NelumboNucifera as a medicinal plants contain phenolic, glycosides, alkaloids ,flavonoids, saponins and tannins that all make NelumboNucifera extract has anti-hyperlipidemic effect that was proven $b^{3}$. Nelumbo (Lotus) caused lowering in LDL, TGs, VLDL and cholesterol and increase in HDL, so it corrects thehyperlipidemic state either primary hyperlipidemia or induced from diabetes mellitus and so will help in lowering hypertension. The atherogenic index will markedly decrease when use plant extract ${ }^{3}$.

H. Thebaica(Doum) exhibited significant decrease in serum total cholesterol and non-HDL cholesterol in rats. The beneficial dietary hypotensive and hypolipidemic effects of Doum was also tested by some studies and they found that supplementation with the availability of the Doum may be one of the reasons for the reduction of the systolic blood pressure. The reduction in the diastolic blood pressure can also be a problem caused by Doum. However other problems like cholesterol and triglyceride and LDL are also expected to have a larger value as compared to the once who are not given proper treatment once while there is an increase in the HDL value $^{15}$.

Table (1): The effect of HyphaeneThebaica on lipid Profile (Total Cholesterol-Triglycerides-LDL-HDL) and Aginotensin Converting Enzyme (ACE)

\begin{tabular}{|c|c|c|c|}
\hline Author-Year-Country & $\begin{array}{c}\text { Number of } \\
\text { experimental } \\
\text { Animals }\end{array}$ & $\begin{array}{c}\text { Type of } \\
\text { extract }\end{array}$ & Results \\
\hline $\begin{array}{c}\text { AlharbiNG,Sindi HA.(2020)( } \\
\text { KSA)16 }\end{array}$ & 56 male rats & Water extract & Significance increase in HDL.( P<0.05) \\
\hline $\begin{array}{c}\text { Abdulazeez MA et al.,(2019)( } \\
\text { Nigeria)7 }\end{array}$ & 25 rats & $\begin{array}{c}\text { Flavonoid rich } \\
\text { fraction of HT }\end{array}$ & Significant reduction in ACE (P<0.05) \\
\hline
\end{tabular}


Cont... Table (1): The effect of HyphaeneThebaica on lipid Profile (Total Cholesterol-Triglycerides-LDL-HDL) and Aginotensin Converting Enzyme (ACE)

\begin{tabular}{|c|c|c|c|}
\hline $\begin{array}{l}\text { Hassan MK et al.,(2018) ( } \\
\text { Egypt) } 17\end{array}$ & 32 male rats & $\begin{array}{l}\text { Ethanolic } \\
\text { extract }\end{array}$ & $\begin{array}{l}\text { Significant reduction in cholesterol, TGs, LDL. } \\
\qquad(\mathrm{P}<0.05)\end{array}$ \\
\hline $\begin{array}{c}\text { BayadA.B, } \\
\text { 2016(Egypt)18 }\end{array}$ & $\begin{array}{l}18 \text { male and female } \\
\text { rats }\end{array}$ & Decoction & $\begin{array}{c}\text { Significant decrease in lipids }(\text { cholesterol, TG, Total } \\
\text { lipids })(\mathrm{P}<0.05)\end{array}$ \\
\hline $\begin{array}{l}\text { Elhaj A.E, Elbagir NM,(2016) } \\
\text { (Sudan)19 }\end{array}$ & 40 male rats & Powder & $\begin{array}{l}\text { Significant reduction in cholesterol, TGs, LDL. } \\
\qquad(\mathrm{P}<0.05)\end{array}$ \\
\hline $\begin{array}{l}\text { Al-Gendy A et al.,(2008) } \\
\text { (Egypt) } 15\end{array}$ & 30 individual & Water extract & $\begin{array}{l}\text { Significant reduction in systolic and diastolic B1. } \\
\text { Pressure and blood cholesterol( } \mathrm{P}<0.001)\end{array}$ \\
\hline $\begin{array}{l}\text { Zanna H et al., } \\
\text { (2008)20 }\end{array}$ & 60 male rats & Aqueous & Significance decrease cholesterol in serum $(\mathrm{P}<0.05)$ \\
\hline
\end{tabular}

Table(2): The effect of NelumboNucifera on Lipid Profile and Aginotensin Converting Enzyme (ACE)

\begin{tabular}{|c|c|c|c|}
\hline Author-Year-Country & $\begin{array}{l}\text { Number of } \\
\text { experimental } \\
\text { Animals }\end{array}$ & Type of extract & Results \\
\hline $\begin{array}{l}\text { Alok B,(2017) } \\
\quad(\text { India }) 5\end{array}$ & 30 albino Wistar rats & Alcoholic extract & $\begin{array}{l}\text { Significant hypocholesterolemic } \\
\qquad \operatorname{effect}(\mathrm{P}<0.05)\end{array}$ \\
\hline Keshav RP,(2015)(Nepal)6 & - & $\begin{array}{l}\text { Water and alcoholic } \\
\text { extract }\end{array}$ & Anti-dyslipidemia effect \\
\hline $\begin{array}{l}\text { Subasini U,(2014) } \\
\text { ( India) } 3\end{array}$ & 36 rats & $\begin{array}{l}\text { Hydro-alcoholic flower } \\
\text { extract }\end{array}$ & $\begin{array}{l}\text { Significant decrease in lipid } \\
\text { profile }(\mathrm{P}<0.001) \text { and increase } \\
\qquad \mathrm{HDL}(\mathrm{P}<0.001)\end{array}$ \\
\hline $\begin{array}{l}\text { Velusami VC etal.,(2013) } \\
\text { (India) } 21\end{array}$ & - & Ethanolic extract & $\begin{array}{c}\text { Significant Antihyperlipidemic and } \\
\text { increase } \operatorname{HDL}(\mathrm{P}<0.05)\end{array}$ \\
\hline $\begin{array}{l}\text { Vinodhini R,(2010) } \\
\text { ( Ethiopia)22 }\end{array}$ & & $\begin{array}{c}\text { Flowers of } \\
\text { NelumboNucifera }\end{array}$ & $\begin{array}{l}\text { Significant reduction in } \\
\text { cholesterol }(\mathrm{P}<0.001)\end{array}$ \\
\hline
\end{tabular}




\section{Discussion}

Hyperlipidemia can be considered as one of the probable condition which can induce a large number of genetic and the acquired issues and disorders in the human body. We can also recall and redefine as the improved levels of the lipids inside the human body. A further value of the LDL i.e. Low Density Lipoprotein along with the increase of Cholestrol level, or it can be a probable reason for the improved triglyceride levels. The general ingredients of the lipids includes various types of cholesterol levels, or the values of lipoproteins, in association with the chylomicrons, VLDL, LDL, Apo lipoproteins. The Hyperlipidemia is also associated to the promotion of the atherosclerosis which is available in blood vessels. However it might also affect the heart which might lead to the improved ischemia injury ${ }^{12}$. Most of hypertensive patients have to proceed by cardiovascular diseases, DM or dyslipidemia. Obesity, metabolic syndrome, alcoholic intake and smoking are risk factors cause increase in cerebrovascular and renal complications. Familial history of hypertension, hypercholesterolemia and diabetes playan important role ${ }^{13}$.

Angiotensin-converting enzyme (ACE) regulates the blood pressure as a central entity which is responsible for the regulation of the pressure in the blood vessel which is supposed to be regulating the management of the pressure. ACE tends to contract the blood vessels and this is responsible for the increase of the blood vessels. The decrease as well as increase of the blood pressure depends on the blood pressure of the human body. ACE inhibitors are very important and used in a large number of quantity as pharmaceutical drugs responsible for the treatment of the diseases relative to cardio issues ${ }^{14}$.

Therapeutic use of the Medicinal plants is done with a proper belief that they are a rich source of chemical substances which are needed for the human body and protective against developing side effects, but many researches have been done to prove its efficacy and safety $^{14}$.
Due to its phytochemical constituents like phenolic , glycosides, alkaloids ,flavonoids, saponins and tannins that all make NelumboNucifera extract and HyphaeneThebaica have anti-hyperlipidemic effect they caused lowering in LDL, TGs, VLDL and cholesterol and increase in HDL, so it corrects the hyperlipidemic state either primary hyperlipidemia or induced from DM and so will help in lowering hypertension. The atherogenic index will markedly decrease when use plant extract ${ }^{3}$ and ${ }^{15}$.

From the results of previous studies shown in Table(1) it was proved that according to chemical composition of Hyphaene and its content of flavonoids ,it has a good anti hyperlipidemic effect that proved by ${ }^{16}$ by using water extract on 56 male rats ,it showed that Hyphaene had a significant effect on increasing $\operatorname{HDL}(\mathrm{P}<0.05) .{ }^{7}$,proved that flavonoid rich fraction of Hyphaene cause significant decrease in ACE when given to 32 rat $(\mathrm{P}<0.05)^{7}$. Also Hassan et al., showed that Ethanolic extract of Hyphaene caused decrease in serum levels of TG, cholesterol and LDL ${ }^{17}$.NelumboNucifera has many useful component like flavonoids,tannis and saponins that make it benefit in treatment hyperlipidemia and hypertension. ${ }^{5}$ proved that by alcoholic extract in the experiment on 30 male rats, there was significant hypocholesterolemic effect. $(\mathrm{P}<0.05)^{5}$.Also ${ }^{6}$ showed that by water and alcoholic extract, the plant had antidyslipidemic effect ${ }^{6}$. Also, ${ }^{3}$ proved that hydroalcoholic flower extract decreased the lipid profile) $\mathrm{P}<0.001$ ).

\section{Conclusion}

Extracts of Hyphaene and Nelumbo are hypolipidemic and so, anti-hypertensive due to its constituents of active substances that enables them to be used as therapeutic agents in treating hyperlipidemic hypertensive patients. We conclude thatDoum and Lotus are lowering factors for serum cholesterol and other lipid profile and it lowers ACE,so control the hypertension will be done.

Ethical Clearance: The researchers were able to ask permission to conduct the study and were given permission to conduct the experiments. 
Source of Funding: There was no fund produced from any organization.

Conflict of Interest: There is no conflict of interest.

\section{References}

1. Rathod, P. and R.P.J.J.o.H.M. Yadav, Antidiabesity potential of various multifunctional natural molecules. 2021: p. 100430.

2. Mohamed, A.A., A.A. Khalil, and H.E.J.G.Y.A. ElBeltagi, Antioxidant and antimicrobial properties of kaff maryam (Anastatica hierochuntica) and doum palm (Hyphaene thebaica). 2010. 61(1): p. 67-75.

3. Subasini, U., et al., Phytochemical analysis and anti hyperlipidemic activity of nelumbo nucifera in male wistar rats. 2014. 5(1): p. 935-940.

4. Salam, M.A., et al., Study of the possible antihypertensive and hypolipidemic effects of an herbal mixture on 1-name-induced hypertensive rats. 2016. 9(5): p. 85-90.

5. Bhardwaj, A. and K.P.J.I.J.P.P.S. Modi, ANTIDIABETIC AND ANTIHYPERLIPIDAEMIC ACTIVITY OF NELUMBO NUCIFERA GAERTN ETHANOL SEED EXTRACT IN STREPTOZOTOCIN INDUCED DIABETIC RATS. 2017. 9: p. 197204.

6. Paudel, K.R., N.J.E.-B.C. Panth, and A. Medicine, Phytochemical profile and biological activity of Nelumbo nucifera. 2015. 2015.

7. Abdulazeez, M., et al., Antioxidant, hypolipidemic and angiotensin converting enzyme inhibitory effects of flavonoid-rich fraction of Hyphaene thebaica (Doum Palm) fruits on fat-fed obese wistar rats. 2019: p. 1-11.

8. Shukla, K. and N.J.I.H. Chaturvedi, Investigation on preliminary phytochemical and proximate analysis of Nelumbo nucifera Gaertn seeds. 2015. 4: p. 35-43.

9. Panthari, P., et al., Investigations on Myrica nagi leaves: phytochemical screening and physicochemical evaluation. 2013. 2(5): p. 28672873.
10. Aamer, R.A.J.A.o.A.S., Characteristics of aqueous doum fruit extract and its utilization in some novel products. 2016. 61(1): p. 25-33.

11. Habib, D., et al., Hypolipidemic efficacy of hyphaenethebaica (doum) in experimental nephrotic syndrome. 2014. 4: p. 28-34.

12. Yao, Y.S., et al., Mechanisms underlying direct actions of hyperlipidemia on myocardium: an updated review. 2020. 19(1): p. 1-6.

13. Mach, F., et al., 2019 ESC/EAS Guidelines for the management of dyslipidaemias: lipid modification to reduce cardiovascular risk. 2020. 41(1): p. 111188.

14. Kaplan, J.A., Essentials of Cardiac Anesthesia for Noncardiac Surgery E-Book: A Companion to Kaplan's Cardiac Anesthesia. 2018: Elsevier Health Sciences.

15. El-Gendy, A., et al., The beneficial dietary hypotensive and hypolipidaemic effects of Hyphaene thebaica (Doum). 2008. 7(1): p. 1-7.

16. Alharbi, N.G. and H.A.J.L.S.J. Sindi, Effect of Doum (Hyphaene Thebaica) Fruit Water Extract on hypercholesteremic Rats. 2020. 17(3).

17. Abdel-Farid, I.B., et al., Metabolomic Profiling and Biological Activity of Hyphaene thebaica and Medemia argun: A review. 2019. 6(1): p. 01-16.

18. Bayad, A.E.J.M., Influences of doum fruit Hyphaene thebaica extract on the reproductive parameters, blood picture, lipid profile and hepatorenal functions in rats. 2016. 4: p. 384-391.

19. Elhaj, N.A. and N.M.J.E.a. ElBagir, Hypolipidemic effect of Hyphaene thebaica (Doum-palm) in induced hypercholestrolemic wistar albino rats. 2016.

20. Zanna, H., et al., Effects of aqueous suspension of the root of Hyphaene thebaica (L:) mart on some indicators of liver and kidney function in rats. 2008. 3(4): p. 330-334.

21. Velusami, C.C., et al., Effect of Nelumbo nucifera petal extracts on lipase, adipogenesis, adipolysis, and central receptors of obesity. 2013. 2013.

22. Vinodhini, R.J.I.t., Detoxifying effect of Nelumbo nucifera and Aegle marmelos on hematological parameters of Common Carp (Cyprinus carpio L.). 2010. 3(4): p. 127-131. 